\title{
High prevalence of celiac disease in patients with type 1 diabetes detected by antibodies to endomysium and tissue transglutaminase
}

\author{
PM Gillett MRCPUK MRCPCH ${ }^{1}$, HR Gillett MD MRCPUK ${ }^{3}$, DM Israel MD FRCPC ${ }^{1}$, \\ DL Metzger MD FAAP FRCPC ${ }^{2}$, L Stewart MD FRCPC ${ }^{2}$, J-P Chanoine MD $^{2}$, HJ Freeman MD FRCPC 3
}

PM Gillett, HR Gillett, DM Israel, et al. High prevalence of celiac disease in patients with type 1 diabetes detected by antibodies to endomysium and tissue transglutaminase. Can J Gastroenterol 2001;15(5):297-301.

OBJECTIVE: To establish the prevalence of celiac disease (CD) in children with type 1 diabetes in British Columbia.

PATIENTS AND METHODS: Two hundred thirty-three children with type 1 diabetes were prospectively screened for CD using blind testing with the current 'gold standard', immunoglobulin A endomysium antibody (EmA), and the novel immunoglobulin A tissue transglutaminase (tTG) antibody. Those children with positive results were offered small bowel biopsy; a gluten-free diet was recommended if CD was confirmed. RESULTS: Nineteen children were positive for EmA and had an elevated tTG level. One patient from this group was already known to have $C D$, and the other 18 patients consented to biopsy. One biopsy was normal, three biopsies demonstrated elevated intraepithelial lymphocyte counts with normal morphology and 14 biopsies had morphological changes consistent with CD. Growth parameters were normal in all patients, and nine of 19 children who were positive for EmA were asymptomatic. Seven patients had mild elevation of tTG levels alone. Two children from this latter group had normal biopsies, and five declined biopsy.

CONCLUSIONS: At least 14 new cases of CD were detected in addition to four known cases, yielding an overall biopsyconfirmed prevalence of CD of $7.7 \%$ (18 of 233). The present study confirms that $\mathrm{CD}$ is as prevalent in the pediatric type 1 diabetic population in British Columbia as it is in Europe. Serological screening of these children is important because many children have no symptoms or signs suggestive of $\mathrm{CD}$. This study suggests that tTG serology may also be useful in monitoring response and compliance with a gluten-free diet.

Key Words: Antiendomysium antibodies; Anti-tissue transglutaminase antibodies; Celiac disease; Children; Type 1 diabetes

Forte prévalence de la maladie cæliaque chez des patients souffrant de diabète de type 1 décelée par les anticorps dirigés contre l'endomysium et la transglutaminase tissulaire OBJECTIF : Établir la prévalence de la maladie cæliaque (MC) chez les enfants souffrant de diabète de type 1 en Colombie-Britannique. PATIENTS ET MÉTHODES : Deux cent trente-trois enfants atteints de diabète de type 1 ont été soumis de façon prospective à un dépistage à l'égard de la MC à l'aide de tests à l'insu standard au moyen de l'anticorps anti-EMA (dirigé contre l'endomysium de l'immunoglobuline A) et le nouvel anticorps anti-TTG (pour transglutaminase tissulaire de l'immunoglobuline A). Les enfants obtenant des résultats positifs ont eu le choix de subir une biopsie du grêle; une alimentation sans gluten a été débutée lorsque la MC était confirmée.

RÉSULTATS : Dix-neuf enfants se sont révélés positifs à l'égard de l'EMA et présentaient un taux élevé de TTG. Un patient de ce groupe voir page suivante

Divisions of ${ }^{1}$ Pediatric Gastroenterology and ${ }^{2}$ Endocrinology, British Columbia's Children's Hospital; ${ }^{3}$ Gastroenterology, University of British Columbia, Vancouver, British Columbia

Correspondence and reprints: Dr David M Israel, Division of Gastroenterology, British Columbia's Children's Hospital, 4480 Oak Street,

Vancouver, British Columbia V6H 3V4. Telephone 604-875-2332, fax 604-875-3244, e-mail disrael@cw.bc.ca

Received for publication May 23, 2000. Accepted January 25, 2001 
avait déjà reçu un diagnostic de MC et les dix-huit autres ont accepté de subir la biopsie. Une biopsie s'est révélée normale; trois ont révélé une hausse des lymphocytes intra-épithéliaux avec morphologie normale et 14 présentaient des anomalies morphologiques concordant avec la MC. Les paramètres de croissance ont été normaux chez tous les patients et 9 enfants sur les 19 qui étaient séropositifs à l'égard de l'EMA étaient asymptomatiques. Sept patients présentaient une légère élévation de leurs taux de TTG seulement. Deux enfants de ce dernier groupe avaient des biopsies normales et cinq ont refusé la biopsie.
CONCLUSION : Au moins 14 nouveaux cas de MC ont été décelés en plus des quatre cas connus, ce qui donne une prévalence globale de cas de $\mathrm{MC}$ confirmée à la biopsie de 7,7 \% (18 sur 233). Cette étude confirme que la $\mathrm{MC}$ existe dans la population pédiatrique atteinte de diabète de type 1 en Colombie-Britannique, tout comme en Europe. Le dépistage sérologique chez ces enfants est important parce que nombre d'entre eux ne présentent ni symptômes ni signes avant-coureurs de MC. Cette étude donne à penser que les dosages de TTG peuvent également être utiles pour vérifier la réponse et la fidélité à la diétothérapie sans gluten.
$\mathrm{C}$ eliac disease (CD) is a small bowel enteropathy caused by a permanent intolerance to gluten in genetically susceptible individuals (1). Despite similar population demographics, it has been suggested that $\mathrm{CD}$ is less prevalent in North America (2) than in Western Europe, where the prevalence approaches one in 200 (3). Physicians in North America have been slow to adapt their practices to the evidence that $\mathrm{CD}$ is common in those of Western European ancestry, and that CD should be considered and actively screened for, particularly in high risk groups (4-7). Screening studies have also shown that many patients are asymptomatic, and do not exhibit the classic symptoms and signs associated with malabsorption (8). European studies have generally found CD in $4 \%$ of children with type 1 diabetes $(9,10)$, and many diabetic clinics routinely screen their patients for CD. Most studies have used immunoglobulin (Ig) A endomysium antibodies (EmA), and IgA and IgG antigliadin antibodies (AGA) to test for CD. In 1997, the antigen for EmA was reported to be tissue transglutaminase (tTG) (11); this allowed for the development of an ELISA.

In the present prospective study, we aimed to determine the prevalence of $\mathrm{CD}$ in children with type 1 diabetes who attended British Columbia's Children's Hospital in Vancouver, British Columbia using the current 'gold-standard' for testing - IgA EmA - and the newly described antibody to tTG.

\section{PATIENTS AND METHODS}

The study was approved by the University of British Columbia Clinical Research Ethics Board. All children with type 1 diabetes who visited the diabetic clinic at British Columbia's Children's Hospital between October 1998 and April 1999 were approached to take part in the study. The study was explained to the patient and their parent or guardian by one of three investigators, and written consent was obtained. Blood was drawn at the clinical visit for an annual thyroid-stimulating hormone screen. If the patient consented to participate in the study, the residual serum from this test was forwarded to the Gastrointestinal Research Laboratory at the University of British Columbia, where serology testing was performed in a blind fashion by a single investigator.

Serum was tested for IgA EmA using indirect immunofluorescence against human umbilical cord as described by
Ladinser et al (12) at a starting dilution of 1 in 5; positive samples were tested at increasing dilutions until fluorescence disappeared.

An ELISA to measure IgA tTG against guinea pig tTG was established using the method of Dieterich et al (13) and validated in 21 untreated adults with $C D, 48$ treated adult celiacs and 128 disease controls (14). A reference range of 140 arbitrary units (AU)/mL or less was calculated to include three standard deviations above the mean (99\% confidence limits). During this validation, it was found that no patient with IgA deficiency and CD had tTG titres higher than $5 \mathrm{AU} / \mathrm{mL}$. Samples with titres of $5 \mathrm{AU} / \mathrm{mL}$ or less were tested for IgA deficiency using the Nor-Partigen Total IgA Kit (Behring Diagnostics Inc, USA).

Patients positive for one or both screening tests were contacted by one of the investigators and advised of the results. They were then seen to assess symptoms and diet, and discuss the implications of the results and the need for biopsy. Upper gastrointestinal endoscopy was performed as an outpatient procedure, with diabetologists overseeing the prescription of fluids and insulin doses. At the insertion of their intravenous cannula, blood was drawn from the patients for blood cell counts, and analysis of glycosylated hemoglobin levels, liver chemistry, albumin levels and total protein levels. Four biopsies of the distal duodenum were taken at endoscopy. Standard histological criteria for the diagnosis of CD were used (15). An elevated intraepithelial lymphocyte (IEL) count was defined as more than 40 IELs per 100 enterocytes (16). Patients with biopsies consistent with $C D$ were then referred for dietetic advice about a gluten-free diet (GFD).

\section{RESULTS}

Of the 236 people who were approached to participate in the study, 233 children with type 1 diabetes agreed to participate; 125 were male and 108 were female. Analysis of ethnic origin revealed that 209 were white, 12 were East Indian, seven were Asian, four were First Nations and one was African. The median age was 12.9 years (range 1.3 to 19.2 years). The median age at diagnosis was 6.9 years (range 0.3 to 16.7 years), and the median duration of diagnosis was 3.9 years (range 0 to 17.1 years). The total number of children with type 1 diabetes followed by the diabetes clinic is 900 . There are a number of smaller clinics in British Columbia that follow children with this con- 
TABLE 1

Patients positive for immunoglobulin A (IgA) endomysium antibody (EmA) and/or having elevated IgA tissue transglutaminase (tTG) antibody titre

\begin{tabular}{|c|c|c|c|c|c|c|c|}
\hline Patient & Age (years) & Sex & Race & Symptoms & $\begin{array}{l}\text { IgA tTG titre } \\
(\mathrm{AU} / \mathrm{mL})^{*}\end{array}$ & IgA EmA titre ${ }^{\dagger}$ & Biopsy \\
\hline 1 & 3.3 & Male & White & None & 900 & $1: 50$ & $\begin{array}{l}\text { Increased intraepithelial } \\
\text { lymphocyte count }\end{array}$ \\
\hline 2 & 3.7 & Female & White & None & 12,800 & $1: 5000$ & Villous atrophy \\
\hline 3 & 5.4 & Female & White & Pain, bloating, constipation & 2100 & $1: 500$ & Villous atrophy \\
\hline 4 & 6.1 & Female & White & Pain & 1075 & $1: 100$ & Normal \\
\hline 5 & 9.0 & Male & White & Constipation & 14,300 & $1: 2500$ & Villous atrophy \\
\hline 6 & 10.5 & Female & White & Diarrhea, pain, nausea & 315 & $1: 10$ & $\begin{array}{l}\text { Increased intraepithelial } \\
\text { lymphocyte count }\end{array}$ \\
\hline 7 & 10.8 & Female & White & Pain & 4000 & $1: 1000$ & Villous atrophy \\
\hline 8 & 11.5 & Female & White & None & 2380 & $1: 1000$ & $\begin{array}{l}\text { Increased intraepithelial } \\
\text { lymphocyte count }\end{array}$ \\
\hline 9 & 11.9 & Male & White & Diarrhea, pain & 14,000 & $1: 2500$ & Villous atrophy \\
\hline 10 & 12.3 & Male & White & Diarrhea, pain & 14,720 & $1: 5000$ & Villous atrophy \\
\hline 11 & 13.5 & Male & White & None & 5500 & $1: 500$ & Villous atrophy \\
\hline 12 & 13.7 & Male & White & None & 28,160 & $1: 5000$ & Known celiac disease \\
\hline 13 & 14.3 & Male & White & None & 1250 & $1: 100$ & Villous atrophy \\
\hline 14 & 14.3 & Female & White & None & 12,000 & $1: 1000$ & Villous atrophy \\
\hline 15 & 15.1 & Male & White & Pain, gas & 5700 & $1: 500$ & Villous atrophy \\
\hline 16 & 15.7 & Male & White & None & 13,000 & $1: 5000$ & Villous atrophy \\
\hline 17 & 15.9 & Female & White & None & 8400 & 1:1000 & Villous atrophy \\
\hline 18 & 16.2 & Female & White & Pain, gas & 35,900 & $1: 5000$ & Villous atrophy \\
\hline 19 & 17.4 & Male & White & Pain & 198 & $1: 10$ & Villous atrophy \\
\hline 20 & 3.7 & Male & White & None & 178 & Negative & Not done \\
\hline 21 & 10.1 & Male & White & None & 166 & Negative & Not done \\
\hline 22 & 11.6 & Male & White & None & 235 & Negative & Not done \\
\hline 23 & 11.6 & Female & Asian & None & 433 & Negative & Normal \\
\hline 24 & 16.4 & Male & White & Diarrhea, pain & 410 & Negative & Normal \\
\hline 25 & 17.8 & Female & White & None & 188 & Negative & Not done \\
\hline 26 & 18.8 & Male & White & None & 245 & Negative & Not done \\
\hline
\end{tabular}

*Reference range: $\leq 140 \mathrm{AU} / \mathrm{mL} ;{ }^{\dagger}$ Reference range: negative

dition, and the total number of children aged 0 to 18 years in British Columbia with type 1 diabetes is estimated to be 1450.

Serological results: Nineteen patients $(8.2 \%)$ were positive for $\operatorname{IgA} \mathrm{EmA}$ and had elevated titres of $\operatorname{IgA} \mathrm{tTG}$ (median titre $5700 \mathrm{AU} / \mathrm{mL}$, range 198 to $35,900 \mathrm{AU} / \mathrm{mL}$ ). All of these children were white; 10 were male and nine were female.

One patient with previously biopsy-confirmed CD (patient 12) who was not following a strict GFD had a positive IgA EmA titre at 1 in 5000 dilution and a markedly elevated IgA tTG titre of $28,160 \mathrm{AU} / \mathrm{mL}$. Three other patients previously diagnosed with CD by biopsy who were following a strict GFD had negative IgA EmA titres and normal IgA tTG titres (titres of 24,55 and $75 \mathrm{AU} / \mathrm{mL}$ ). Seven patients $(3.0 \%)$ had elevated levels of IgA tTG (median $188 \mathrm{AU} / \mathrm{mL}$, range 166 to $433 \mathrm{AU} / \mathrm{mL}$ ) but were negative for IgA EmA. Seven patients with IgA tTG levels of $5 \mathrm{AU} / \mathrm{mL}$ or less were tested for IgA deficiency. Only one patient (with a tTG level of $3 \mathrm{AU} / \mathrm{mL}$ ) was IgA deficient. Serum from this patient was sent to the Gastrointestinal Laboratory of the Western General Hospital, Edinburgh, United Kingdom for IgG EmA and IgG AGA testing. The IgG EmA titre was negative, and the IgG AGA level was $85 \mathrm{U}$ (reference range less than $45 \mathrm{U}$ ). He was asymptomatic, and in light of the negative IgG EmA titre, biopsies were not performed, but repeat serology will be offered on an annual basis (Table 1 ).

Small bowel biopsies: All 18 patients who were positive for $\operatorname{IgA} \mathrm{EmA}$ and who had not been previously diagnosed with $\mathrm{CD}$ agreed to endoscopic biopsy. A repeat biopsy was not offered to the patient who was already known to have CD, but the implications of the positive EmA and tTG results were discussed at his next clinic visit, and the importance of the GFD was re-emphasized. The histology results are shown in Table 1 . CD was confirmed in 14 patients, and these patients were advised to commence a GFD, were supplied with an information folder including details about the 
Canadian Celiac Association and had dietetic follow-up arranged for them.

Three patients with positive EmA test results had normal villous morphology on biopsy but an increased IEL count. These children were advised to remain on regular diet with plans to monitor their symptoms and repeat serology testing periodically. The seven patients with an elevated tTG titre alone were contacted about their results, and two patients elected to undergo biopsy. One had a tTG level of $433 \mathrm{AU} / \mathrm{mL}$ and was asymptomatic; the other had a tTG level of $410 \mathrm{AU} / \mathrm{mL}$, and complained of occasional diarrhea and abdominal pain. In both cases, distal duodenal biopsies were normal.

Symptoms and signs: The symptoms of the serology-positive patients are shown in Table 1. Nine of 19 children (47\%) who were positive for EmA had no gastrointestinal symptoms on direct questioning, including six of 14 children (43\%) who had villous atrophy on biopsy. All of these children had normal linear growth, weight gain and pubertal development (data not shown). One child (patient 12) had previously been diagnosed with CD and was asymptomatic, despite being poorly compliant with the GFD; nevertheless, he had chronic iron deficiency anemia and short stature with delayed puberty.

Of the seven patients with raised IgA tTG levels and negative EmA tests, one patient complained of intermittent diarrhea. The other six patients were asymptomatic.

Laboratory results: Four of the EmA-positive patients had evidence of microcytic anemia with decreased hemoglobin and/or mean corpuscular volume. Three patients showed mild increases in transaminase levels, and two patients had decreases in serum albumin and/or protein levels. In total, eight of 19 (42\%) EmA-positive patients had laboratory evidence of anemia and/or altered hepatic function, and all of these patients had biopsy-proven CD.

Prevalence of CD in the study: Fourteen new cases of CD were found on screening, in addition to four patients who were previously diagnosed, yielding a prevalence of $7.7 \%$ (18 of 233) for the pediatric population screened at the diabetic clinic in British Columbia.

\section{DISCUSSION}

Over the past 10 years, studies from Europe $(9,10)$ and North America $(5,7)$ have shown that the prevalence of CD in patients with type 1 diabetes has increased. The association is due to sharing of the human leukocyte antigen alleles DR3 (17) and, by linkage disequilibrium, DQ2. Although IgA AGA serology has been widely used for celiac screening, IgA EmA testing is the screening 'gold standard'. The recent identification of $\mathrm{tTG}$ as the tissue antigen for EmA (11) makes testing for IgA tTG antibodies (by ELISA) a very attractive alternative for first-line screening.

We have confirmed this association by demonstrating an increased prevalence of $\mathrm{CD}$ in type 1 diabetic children in British Columbia. We are unable to comment on the sensitivity and specificity of the two tests in this study because only serologically positive patients were offered biopsy.
Using strict morphological criteria (ie, the presence of villous atrophy), however, the positive predictive value (PPV) of the EmA assay was 14 of 18 (77.7\%). However, if one accepts that elevated IEL counts may represent an early form of CD (18-20) (see below), then the PPV of the EmA is 17 of $18(94.4 \%)$. The PPV of the tTG assay was 14 of 20 (70\%) for children with villous atrophy and 17 of 20 (85\%) if children with increased IEL counts are considered to have $\mathrm{CD}$. While the EmA assay appears to be a more specific test (albeit more subjective), the tTG assay is technically simpler. We speculate that a two-step screening strategy - using the tTG assay as a first step and the EmA assay on those with elevated tTG titres - may simplify screening for CD and make it more cost effective. Further studies are needed to verify this proposal.

In our study, blind testing included four previously diagnosed cases of CD. Three of these children, who were considered to be strictly adherent to their GFD, had tTG levels well within the reference range. The fourth patient (patient 12, Table 1) frequently lapsed from his diet and had a tTG titre in excess of $28,000 \mathrm{AU} / \mathrm{mL}$. Titres of tTG are generally lower in treated than in untreated patients $(13,14,21)$. These studies suggest that tTG serology may also be useful in monitoring response and compliance to a GFD.

The children with positive serology and normal villous architecture but increased IEL counts present a difficult clinical dilemma. Lymphocytic infiltration within the epithelium occurs in the classical mucosal lesion of $\mathrm{CD}$ (22). Similar infiltration in morphologically normal mucosa (with improvement on withdrawal of gluten) was first reported in 'isolated' dermatitis herpetiformis $(18,19)$. Gluten-dependent infiltration in the presence of positive $\operatorname{IgA}$ EmA has since been described in patients without dermatitis herpetiformis (20). It is increasingly accepted that high IEL counts are consistent with gluten-sensitive enteropathy, but because our patients did not meet the current European Society of Paediatric Gastroenterology and Nutrition criteria for the diagnosis of CD (15), a GFD was not recommended. Instead, we proposed close follow-up of symptoms and serology with rebiopsy if indicated.

Relying on typical signs or symptoms to appear before considering a diagnosis of CD leaves a large number of children undiagnosed. Asymptomatic cases accounted for six of 14 (43\%) of those with positive morphology. Of the symptomatic children, one was previously thought to have recurrent abdominal pain (patient 10). Another child (patient 19) had been biopsied two years earlier because of symptoms and, at that time, had no histological abnormalities. This child was diagnosed with type 1 diabetes at the age of eight years and was 15 years old at the time of an initial small bowel biopsy. At that time, the AGA level was less than $1 \mathrm{AU}$. Two years later, the patient was screened again as part of the present study, and the tTG level was 198 $\mathrm{AU} / \mathrm{mL}$, the patient was positive for EmA and the AGA level was $5 \mathrm{AU}$. The latter case shows the importance of repeated screening in high risk populations, even though no clear guidelines have been established. 
It may be argued that asymptomatic children should not be screened. The evidence for early screening relates to the long term risks of undiagnosed CD. The longer the duration of untreated CD (also in dermatitis herpetiformis), the higher the risk of enteropathy-associated T-cell lymphoma (EATCL) (23). Adherence to the diet reduces the risk of EATCL to that seen in the general population. A recent report of four cases documented the association of lymphoma and type 1 diabetes (24). There is also an increased risk of several other nonmalignant long term complications, such as iron-deficiency anemia, osteoporosis, infertility and growth retardation, when patients are poorly compliant with a GFD or when they remain undiagnosed until later life (25). Overall improvement in glucose control with a GFD has been documented in patients with type 1 diabetes and CD (26).

\section{CONCLUSIONS}

The present study confirms an increased prevalence of $\mathrm{CD}$ in children with type 1 diabetes who were followed at British Columbia's Children's Hospital diabetic clinic. All children were white and many were asymptomatic. We suspect that, as found in other studies, the diagnosis of diabetes

\section{REFERENCES}

1. Trier JS. Celiac sprue. N Engl J Med 1991;325:1709-19.

2. Fasano A. Where have all the American celiacs gone? Acta Paediatr Suppl 1996;412:20-4.

3. Catassi C. Screening of coeliac disease. In: Maki M, Collin P, Visakorpi JK, eds. Coeliac Disease. Proceedings of the Seventh International Symposium on Coeliac Disease. Tampere: Coeliac Disease Study Group, 1997:23-4.

4. Not T, Horvath K, Hill ID, et al. Celiac disease risk in the USA high prevalence of antiendomysium antibodies in healthy blood donors. Scand J Gastroenterol 1998;33:494-8

5. Fraser-Reynolds KA, Butzner JD, Stephure DK, Trussell RA, Scott RB. Use of immunoglobulin A-antiendomysial antibody to screen for celiac disease in North American children with type I diabetes. Diabetes Care 1998;21:1985-9.

6. Pueschel SM, Romano C, Failla P, et al. A prevalence study of celiac disease in persons with Down syndrome residing in the United State of America. Acta Paediatr 1999;88:953-6.

7. Hill I, Fasano A, Schwartz R, Counts D, Glock M, Horvath K. The prevalence of celiac disease in at-risk groups of children in the United States. J Pediatr 2000;136:86-90.

8. Collin P, Hallstrom O, Maki M, Viander M, Keyrilainen O. Atypical coeliac disease found with serological screening. Scand J Gastroenterol 1990;25:245-50.

9. Nosari I, Casati A, Mora C, et al. The use of IgA-antiendomysial antibody test for screening coeliac disease in insulin-dependent diabetes mellitus. Diabetes Nutr Metab 1996;9:267-72.

10. Mäki M, Huupponen T, Holm K, Hällstrom O. Seroconversion of reticulin autoantibodies predicts coeliac disease in insulin dependent diabetes mellitus. Gut 1995;36:239-42.

11. Dieterich W, Ehnis T, Bauer M, et al. Identification of tissue transglutaminase as the autoantigen of celiac disease. Nat Med 1997;3:797-801.

12. Ladinser B, Rossipal E, Pittschieler K. Endomysium antibodies in coeliac disease: an improved method. Gut 1994;35:776-8

13. Dieterich W, Laag E, Schöpper H, et al. Autoantibodies to tissue transglutaminase as predictors of celiac disease. Gastroenterology $1998 ; 115: 1317-21$ usually precedes the onset of $\mathrm{CD}$ (the patients in the present study had had their diabetes for a mean of almost four years before $\mathrm{CD}$ was diagnosed). The use of the new tTG assay has proved useful for screening and appears to be reproducibly elevated; however, the EmA assay still appears to be the more discriminatory test. This study strengthens the growing body of evidence that screening for $\mathrm{CD}$ is necessary in patients with type 1 diabetes. Follow-up of patients who were positive on serology, whether positive or negative on biopsy, will give us valuable insight into the natural history of this combination of conditions. In particular, we will learn whether a GFD does indeed improve the overall well being and metabolic control of the patients, as well as reduce the long term risks of $\mathrm{CD}$.

ACKNOWLEDGEMENTS: This study was supported by a grant from the British Columbia's Children's Hospital Research Fund. Peter and Helen Gillett are recipients of the JA Campbell Award for Young Investigator of the Year (1999) from the Canadian Celiac Association

14. Gillett HR, Freeman HJ. Comparison of IgA endomysium antibodies and IgA antibodies to tissue transglutaminase in celiac disease. Gastroenterology 1999:116:G3836. (Abst)

15. Walker-Smith JA, Guandalini S, Schmitz J, Schmerling DH, Visakorpi JK. Revised criteria for diagnosis of coeliac disease. Report of Working Group of European Society of Paediatric Gastroenterology and Nutrition. Arch Dis Child 1990;65:909-11.

16. Ferguson A, Murray D. Quantitation of intraepithelial lymphocytes in human jejunum. Gut 1971;12:988-94

17. Lie BA, Sollid LM, Ascher H, et al. A gene telomeric of the HLA class I region is involved in predisposition to both type 1 diabetes and coeliac disease. Tissue Antigens 1999;54:162-8.

18. Fry L, Seah PP, McMinn R, Hoffbrand AV. Lymphocytic infiltration of epithelium in diagnosis of gluten-sensitive enteropathy. Br Med J 1972;iii:71-4.

19. Fry L, Seah P, Harper P. The small intestine in dermatitis herpetiformis. J Clin Pathol 1974;27:817-24.

20. Picarelli A, Mauiri L, Mazzilli MC, et al. Gluten-sensitive disease with mild enteropathy. Gastroenterology 1996;111:608-16.

21. Trocone R, Maurano F, Rossi M, et al. IgA Antibodies to tissue Transglutaminase: An effective diagnostic test for Celiac disease. J Pediatr 1999;134:166-71.

22. Marsh MN. Studies of intestinal lymphoid tissue IV: The predictive value of raised mitotic indices among jejunal epithelial lymphocytes in the diagnosis of gluten-sensitive enteropathy. J Clin Pathol 1982;35:517-25.

23. Holmes GK, Prior P, Lane MR, Pope D. Malignancy in coeliac disease - effect of a gluten free diet. Gut 1989;30:333-8.

24. O'Connor TM, Cronin CC, Loane JF, et al. Type 1 diabetes mellitus, coeliac disease and lymphoma: a report of four cases. Diabetes Med 1999;16:614-7.

25. Holmes GKT. Non-malignant complications of coeliac disease. Acta Paediatr Suppl 1996;412:68-75.

26. Acerini CL, Ahmed ML, Ross KM, Sullivan PB, Bird G, Dunger DB. Coeliac disease in children and adolescents with IDDM: Clinical characteristics and response to gluten-free diet. Diabetes Med 1998;15:38-44. 


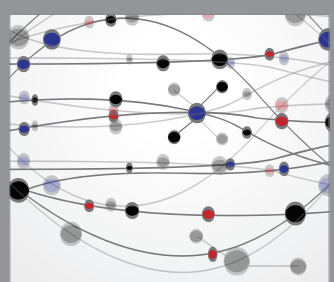

The Scientific World Journal
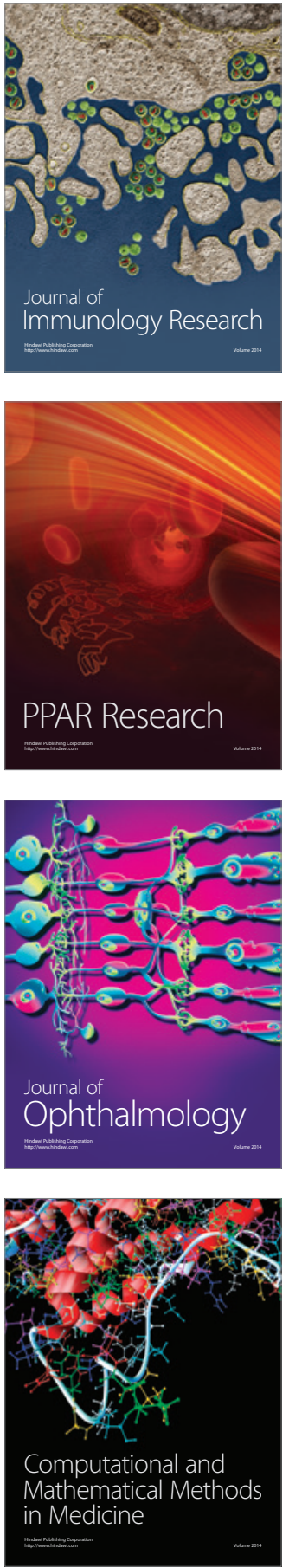

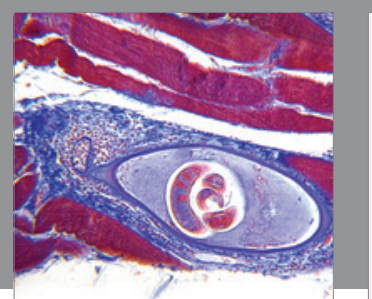

Gastroenterology Research and Practice

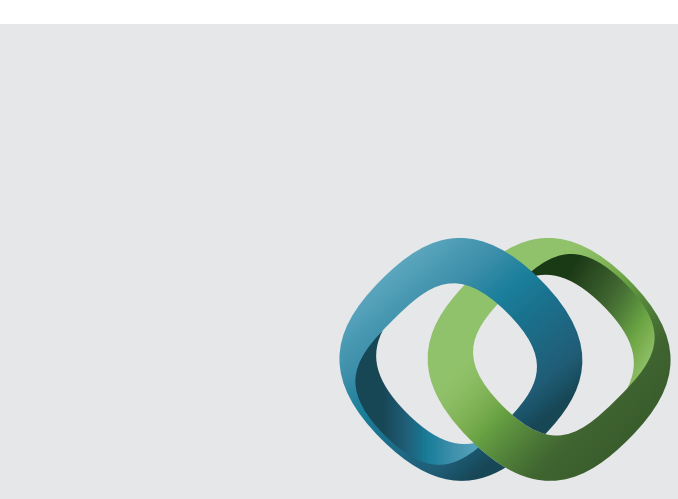

\section{Hindawi}

Submit your manuscripts at

http://www.hindawi.com
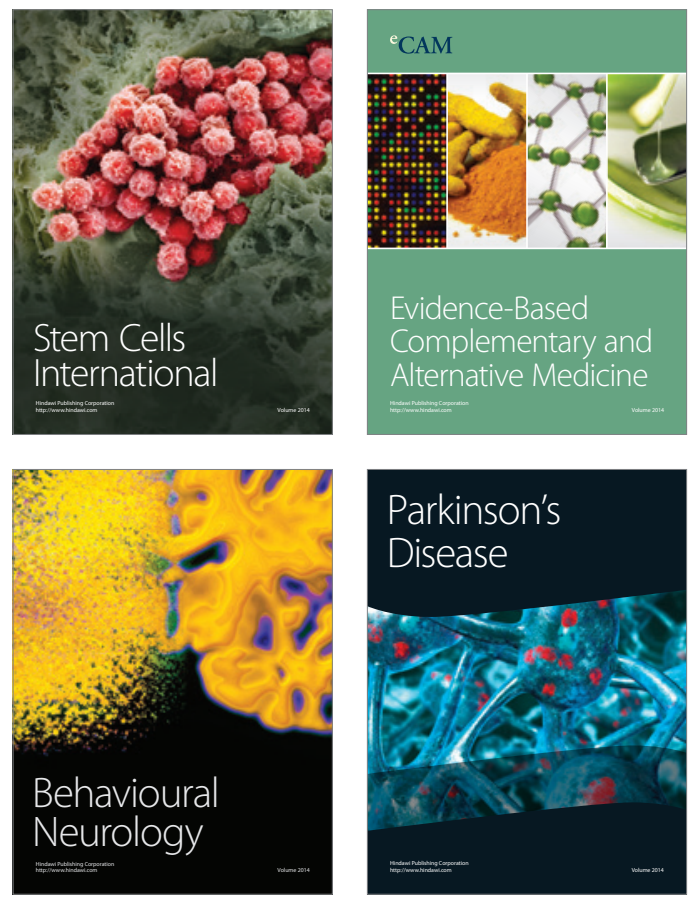
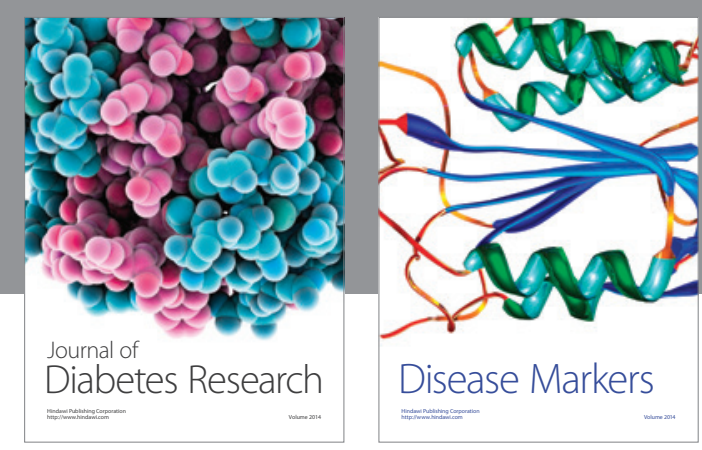

Disease Markers
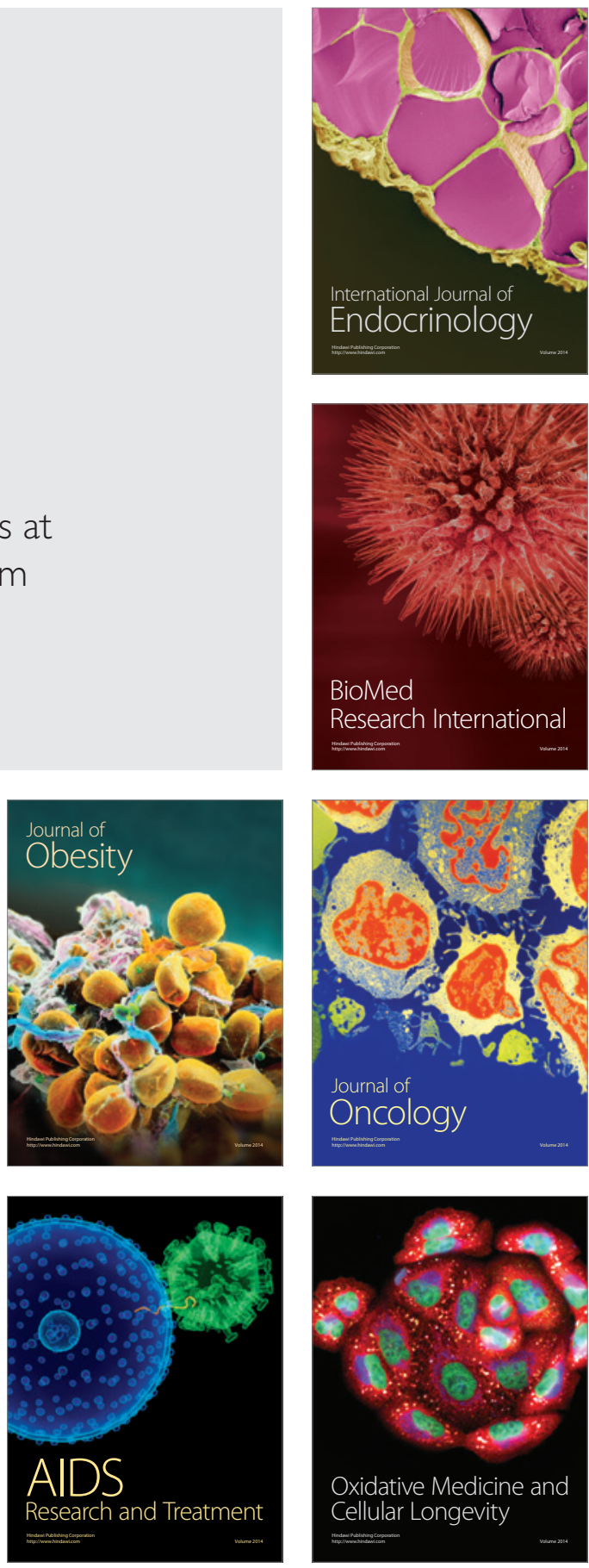